\title{
Role of heat shock protein 27 in gemcitabine-resistant human pancreatic cancer: Comparative proteomic analyses
}

\author{
QING-HUA LIU $^{1,2}$, CHEN-YAN ZHAO $^{1}$, JING ZHANG $^{1}$, YING CHEN $^{1}$, LI GAO $^{1}$, \\ CAN-YONG NI ${ }^{1}$ and MING-HUA ZHU ${ }^{1}$ \\ ${ }^{1}$ Department of Pathology, Changhai Hospital, Secondary Military Medical University, Shanghai; \\ ${ }^{2}$ Department of Pathology, Xuzhou Medical College, Xuzhou, P.R. China
}

Received February 2, 2012; Accepted July 19, 2012

DOI: $10.3892 / \mathrm{mmr} .2012 .1013$

\begin{abstract}
The most notable obstacle hindering the effective treatment of human pancreatic cancer is intrinsic chemoresistance. In order to identify the candidate protein(s) responsible for the intrinsic chemoresistance, the protein expression profiling of human pancreatic adenocarcinoma cell line Capan-1 and its distinct surviving cells following primary treatment with gemcitabine (GEM) were compared by twodimensional electrophoresis (2-DE) combined with liquid chromatography-mass spectrometry (LC-MS) or mass spectrometry (MS). In total, nine proteins were identified, and heat shock protein B1 (HSP27), one of the differentially expressed proteins, was selected for further validation. Furthermore, the results of western blotting and immunohistochemical staining indicated that HSP27 may be significant in pancreatic intrinsic chemoresistance to GEM. The findings of this study provide a platform for further elucidation of the underlying mechanisms of pancreatic cancer intrinsic chemoresistance and demonstrate that HSP27 may be a valid target for anticancer drug development.
\end{abstract}

\section{Introduction}

Pancreatic cancer is the fourth most common cause of cancerrelated mortality worldwide (1). The overall prognosis for patients with pancreatic cancer remains poor; less than $5 \%$ of patients with adenocarcinoma of the pancreas survive for more than 5 years following diagnosis (2). Surgical resection is currently the only potentially curative treatment for pancreatic cancer. However, $80-85 \%$ patients have advanced unresectable disease at diagnosis (2). Chemotherapy is a very important therapeutic strategy for unresectable cancer

Correspondence to: Dr Ming-Hua Zhu, Department of Pathology, Changhai Hospital, Second Military Medical University, 168 Changhai Road, Shanghai 200433, P.R. China

E-mail: mhzhu2000@hotmail.com; mhzhu07@126.com

Key words: pancreatic cancer, intrinsic chemoresistance, proteomics, gemcitabine, heat shock protein 27 patients. Gemcitabine (GEM) and 5-fluorouracil (5-FU) are the common chemotherapy drugs used to treat advanced pancreatic cancer. Gemcitabine (2'-deoxy-2'-difluorodeoxycytidine: Gemzar; GEM) is a deoxycytidine analogue with structural and metabolic similarities to cytarabine. Currently, this nucleoside analogue appears to be the only clinically effective drug for pancreatic cancer, and has shown improvement in overall survival and quality of life (3-6). However, many clinical trials have shown that GEM alone or GEM in combination with other drugs is not likely to achieve marked success and the acquisition of resistance during chemotherapy may further limit the therapeutic success $(7,8)$. Even if a potentially curative surgical resection can be performed, the five-year overall survival is low at $10-25 \%$, mostly due to an almost complete chemoresistance which may be inherent and/ or acquired $(9,10)$. Many studies have been directed towards understanding the mechanism of chemotherapy response and resistance, with the ultimate goal of identifying molecular markers that allow the prediction of chemotherapy response. For pancreatic adenocarcinoma, the process of finding new chemotherapeutics has been exceedingly slow and disappointing. To date, there has been no significant breakthrough in the treatment of pancreatic cancer. Therefore, identifying novel molecular markers related to GEM resistance would be helpful to further understand the exact mechanisms of chemoresistance and produce more effective chemotherapy strategies for patients with pancreatic cancer in the future.

Due to intrinsic chemoresistance, chemotherapeutic drugs usually fail to kill all tumor cells at clinically tolerated doses. The presence of surviving cells above a certain threshold following primary therapy increases the relapse occurrence, which may then generate acquired and more complex resistance phenotypes as a result of sequential genetic changes over long periods of time $(11,12)$. These surviving cells may either be pre-existent or may be generated as a direct result of the chemotherapy itself. Recently, we introduced a new model for the study of de novo drug resistance of pancreatic cancer, which involves the utilization of surviving cancer cells following primary drug treatment. The surviving cells are potentially drug-resistant and exhibit similar growth and tumorigenic potentials to their untreated parental cells (13). In this study, we investigated the differential expression of proteins in these stably surviving cells and cells with or without GEM treatment 
to screen candidate molecules related to intrinsic chemoresistance. In addition, we studied whether these proteins may be used clinically as biomarkers of gemcitabine sensitivity in tumor specimens.

\section{Materials and methods}

Cell lines and materials. The pancreatic cancer cell line Capan-1 (ATCC, Manassas, VA, USA) was used in this study. Capan-1 was cultured in IMDM (Gibco, Carlsbad, CA, USA) containing $20 \%$ fetal calf serum (Gibco), $100 \mathrm{U} / \mathrm{ml}$ penicillin and $100 \mathrm{U} / \mathrm{ml}$ streptomycin. The cells were cultured at $37^{\circ} \mathrm{C}$, in $5 \% \mathrm{CO}_{2}$ and $95 \%$ relative humidity. The drug used in this study was GEM (Lilly, France).

Sample preparation and protein extraction. Capan-1 cells were exposed to GEM at a concentration of $2,000 \mu \mathrm{g} / \mathrm{ml}$ (to obtain a cell survival rate of $<15 \%$ ) for $72 \mathrm{~h}$. The cells were then washed twice with phosphate-buffered saline (PBS) solution, and cultured in drug-free media for another 7 days. The surviving cells were then washed twice with PBS, trypsinized and counted. Non-viable cells were excluded using Trypan blue staining. Control cells were counted when the drug treatment was completed. The viable cell rate was calculated as the number of surviving cells divided by the number of control cells x $100 \%$. A ReadyPrep ${ }^{\mathrm{TM}}$ Protein Extraction kit (total protein) (Bio-Rad, Hercules, CA, USA) was used for control and surviving cells according to the manufacturer's instructions. The cells were washed 3 times with PBS, centrifuged at $800 \mathrm{rpm}$ for $5 \mathrm{~min}$, the supernatant was discarded, and the cells were lysed to produce protein lysates. The mixture was then sonicated for $30 \mathrm{sec}, 3$ times (pulse duration of $30 \mathrm{sec}$ on and $15 \mathrm{sec}$ off) in an ice bath sonicator. Finally, the sample was centrifuged at $12,000 \mathrm{rpm}$ at $20^{\circ} \mathrm{C}$ for $30 \mathrm{~min}$, and the supernatant was collected. The protein cleanup was performed according to the manufacturer's instructions using the ReadyPrep ${ }^{\mathrm{TM}}$ 2-D Cleanup kit (Bio-Rad) and the dry proteins were diluted with rehydration buffer (8 M urea, $4 \%$ CHAPS). The concentration of the prepared protein samples was determined by the Shanghai Generay Biotech Co., Ltd. (China) BCA protein assay according to the manufacturer's instructions. The samples were stored at $-80^{\circ} \mathrm{C}$ until further analysis.

Two-dimensional gel electrophoresis (2-DE) and silver staining. Firstly, $250 \mu \mathrm{g}$ protein was diluted with rehydration buffer [ $8 \mathrm{M}$ urea, $4 \%$ CHAPS, $65 \mathrm{mM}$ DTT, $0.2 \%$ (w/v) Bio-Lyte (Bio-Lyte 3/10 ampholyte, 40\%, Bio-Rad) and $0.001 \%$ bromophenol blue] to $350 \mu \mathrm{l}$ for isoelectric focusing (IEF). IEF was applied on IPG strips (ReadyStrip IPG Strips, pH 3-10, 17 cm, Bio-Rad) with a Protean IEF system (Bio-Rad) according to the following protocol: active hydration $(50 \mathrm{~V}$ for $14 \mathrm{~h}$ ), higher voltage liner ( $250 \mathrm{~V}$ for $30 \mathrm{~min}$ ), rapid cleanup $(1,000 \mathrm{~V}$ for $1 \mathrm{~h}$ ), boost voltage (liner, $10,000 \mathrm{~V}$ for $5 \mathrm{~h}$ ) and isoelectric focus (rapidly, $10,000 \mathrm{~V}$ for a total $60,000 \mathrm{kVh}$ ). Strips were then equilibrated at room temperature for $15 \mathrm{~min}$ in $10 \mathrm{ml}$ equilibration solution [6 $\mathrm{M}$ urea, $0.375 \mathrm{M} \mathrm{pH} 8.8$ Tris- $\mathrm{HCl}, 20 \%$ glycerol, $2 \%$ sodium dodecyl sulfate (SDS), $2 \%$ DTT] and incubated for another $15 \mathrm{~min}$ in an equilibration solution that was the same as previously used, with the exception of replacement of DTT with $2.5 \%$ iodoacetamide. The two-dimensional electrophoresis was performed on 12\% SDS gels with a Protean II xi system (Bio-Rad). The SDS-PAGE gels were run at $5 \mathrm{~mA} / \mathrm{gel}$ (until the proteins had run out of the strips) and then at $25 \mathrm{~mA} / \mathrm{gel}$ until the bromophenol blue dye front reached the bottom of the gels. Three 2-D gels per sample were run to guarantee reproducibility. Following 2-DE, proteins were visualized by silver-staining according to the manufacturer's instructions (Bio-Rad): Fixing (acetic acid $100 \mathrm{ml}$, ethanol $400 \mathrm{ml}$ and pure water up to $1,000 \mathrm{ml}$ ) for $120 \mathrm{~min}$; incubation $(150 \mathrm{ml}$ ethanol, $34 \mathrm{~g}$ Na-acetate, $1 \mathrm{~g}$ $\mathrm{Na}_{2} \mathrm{~S}_{2} \mathrm{O}_{3} \cdot 5 \mathrm{H}_{2} \mathrm{O}$ and pure water to $500 \mathrm{ml}$ ) for $30 \mathrm{~min}$; washing (pure water) $3 \times 5 \mathrm{~min}$; silvering $\left(\mathrm{AgNO}_{3} 0.8 \mathrm{~g}\right.$, add pure water to $500 \mathrm{ml}$ ) for $20 \mathrm{~min}$; washing (pure water) $2 \mathrm{x} 1 \mathrm{~min}$; development $\left(12.5 \mathrm{~g} \mathrm{Na}_{2} \mathrm{CO}_{3}, 200 \mu \mathrm{l}\right.$ formaldehyde and pure water to $500 \mathrm{ml}) 8-10 \mathrm{~min}$; stopping (200 $\mathrm{ml}$ acetic acid and pure water to $500 \mathrm{ml}$ ); washing (pure water) $3 \times 5 \mathrm{~min}$; and preserving $\left(4^{\circ} \mathrm{C}\right.$, packaged by preservative film).

Visualization and image analysis. The silver-stained gels were scanned using a GS- $800^{\mathrm{TM}}$ calibrated densitometer (Bio-Rad) with 300 dpi and analyzed using PDQuest software (version 7.0, Bio-Rad). Protein spots were detected automatically, and manual spot editing or deleting was performed when required. Only those protein spots for which the greatest alterations were $>1.5$-fold between control cells and the surviving cells after GEM treatment were selected for further characterization using mass spectrometry. The protein spots that were selected were sent to Shanghai Unlimit Biotechnology Co., Ltd. (China) for mass spectrometric analysis.

In-gel digestion. Briefly, spots of interest were excised from the 2-DE gels and were placed in deionized water to soak. After washing with deionized water, the spots of interest were centrifuged, supernatant was absorbed, calcium ammonium nitrate (CAN) was used to condense the gel, and samples were vacuum dried. Then, $45 \mathrm{mM}$ DTT/25 mM NH $\mathrm{HCO}_{3}$ was added and the mixture was left to react for $1 \mathrm{~h}$ at $56^{\circ} \mathrm{C}$. Subsequently, the mixture was cooled to room temperature, centrifuged, the supernatant was discarded and the sample was reacted in the dark for $45 \mathrm{~min}$ with $100 \mathrm{mM}$ iodoacetoamide $/ 25 \mathrm{mM}$ $\mathrm{NH}_{4} \mathrm{HCO}_{3}$. The mixture was then centrifuged, the supernatant was discarded, $25 \mathrm{mM} \mathrm{NH}_{4} \mathrm{HCO}_{3}$ was added, then the sample was vibrated for 3-5 min, then centrifuged, the supernatant was discarded, acetonitrile (ACN) was added to condense the gel, the sample was vibrated and vacuum dried. The proteins in-gel were then digested with a tryptic enzyme, firstly at $4^{\circ} \mathrm{C}$ for $30 \mathrm{~min}$, secondly at $37^{\circ} \mathrm{C}$ for $12-16 \mathrm{~h}$, and lastly were sonicated for 10 min with $50 \% \mathrm{ACN} / 5 \%$ formic acid. The sample was then centrifuged, the supernatant was collected in another eppendorf pipe and 50\% ACN/5\% formic acid was added to the pre-pipe. The sample was sonicated, centrifuged, the supernatant of the pre-pipe was collected and the supernatants were mixed. The supernatants were condensed to $10 \mu l$ in a speed-vacuum drier for mass spectrometric analysis.

Liquid chromatography-mass spectrometry detection and analysis. The tryptic peptides were added to an opposite enriching column $[(\mathrm{C} 18,5 \mu \mathrm{m}, 300 \AA$, 300- $\mu \mathrm{m}$ inner diameter x5 mm; Dionex/LC Packings), velocity (10 $\mu \mathrm{l} / \mathrm{min})$, mobile phase (3\% ACN, 0.1\% FA)]. The enriching column was in 
series with another opposite analytical column (Dionex/LC Packings, C18, 75- $\mu \mathrm{m}$ inner diameter, $150 \mathrm{~mm}$ length). The peptides were eluted using a QStar-XL mass spectrograph (MDS Sciex/Applied Biosystems) with NanoESI ion source at a velocity of $250 \mu \mathrm{l} / \mathrm{min}$. The liquid phase system of Nano UPLC (Waters) provided gradient elution: mobile phase A, $0.1 \%$ formic acid $/ \mathrm{H}_{2} \mathrm{O}$; and mobile phase $\mathrm{B}, 0.1 \%$ formic acid/ acetonitrile. The gradient was 5-50\% B (60 min), 50-90\% B (30 min) and 90\% B (15 min).

The parameter settings of the ion source were voltage $3,000 \mathrm{~V}$, assisting nitrogen $0.2 \mathrm{~L} / \mathrm{h}$ and temperature $100^{\circ} \mathrm{C}$. Chromatography-cascade spectrum acquisition was performed in data dependent acquisition (DDA) mode. There were 8 highest-ionic strength at first level of the spectrum and the 2-4 electrically charged peptides had been selected for cracking. The scanning area of first level of the spectrum was $450-1,800 \mathrm{~m} / \mathrm{z}$ and the scanning area of the chromatographycascade spectrum was $50-1,800 \mathrm{~m} / \mathrm{z}$.

The chromatography-cascade spectrum searched human protein databases (ftp://ftp.ebi.ac.uk/pub/databases/IPI/ Current, version ipi.HUMAN.v3.57.fasta), and the software used for research was Mascot (http://www.matrixscience.com). The quality tolerance of the chromatography-cascade spectrum was 0.3 Da, the maximal enzyme digestion omissive spot was 2 , and potential modifiers were carbamoylmethylation of cysteine, oxidize of methionine and phosphatase of serine and tyrosine.

Western blot analysis. Equivalent amounts of total protein $(80 \mu \mathrm{g})$ and the nuclear and cytoplasm proteins (40 $\mu \mathrm{g}$ respectively, according to the protocol of the extraction of nuclear and cytoplasm protein kit, KeyGen Biotech, China) were loaded in each lane and were fractioned by electrophoresis on $12 \%(\mathrm{w} / \mathrm{v})$ SDS-PAGE gels (Mini-Protean3, Bio-Rad), then transferred onto a PVDF membrane using Mini Trans-Blot (Bio-Rad) and blocked with TBST containing 5\% BSA at $4{ }^{\circ} \mathrm{C}$ overnight. The PVDF membrane was probed with a 1:2,000 dilution of rabbit anti-heat shock protein B1 (HSP27) polyclonal antibody (ab5579, Abcam, Cambridge, UK). Horseradish peroxidase-conjugated goat anti-rabbit IgG at a dilution of 1:5,000 was used as a secondary antibody. The protein bands were visualized using the ECL system. The same membrane was reblotted with mouse affinity purified anti-GAPDH antibody (Shanghai Kangcheng Biotech Co. Ltd., China) for total protein and cytoplasm protein, and anti-lamin B1 antibody (KeyGen Biotech) for nuclear protein, at a dilution of 1:2,000, to confirm equal loading.

Patients and specimens. The pancreatic ductal adenocarcinoma (PDAC) specimens were collected with informed consent from 47 patients undergoing radical resection of primary PDAC in Changhai Hospital, Second Military Medical University during 2003-2007. The patients were selected based on a distinctive pathological diagnosis of PDAC according to the World Health Organization classification of tumors of the digestive system (2010). All the experimental procedures were approved by the Research Ethics Committee of the Second Military University. The medical records of the patients were retrospectively reviewed, and the demographic, clinicopathological and treatment data were also collected. The tumor location and size were obtained from the surgical report. Patients receiving preoperative chemotherapy or radiotherapy were excluded from the study.

Immunohistochemistry analysis. Tissue microarrays were constructed using the 47 paraffin-embedded tumor tissue specimens by a precision arraying instrument (Beecher Instruments, Silver Spring, MD, USA). In each case, three tumor cores and two surrounding non-tumor tissues were selected. The sections from the tissue microarray blocks were deparaffinized, rehydrated and then heated in $0.01 \mathrm{~mol} / \mathrm{l}$ sodium citrate buffer (pH 6.0) for $8 \mathrm{~min}$ at $95^{\circ} \mathrm{C}$. Following incubation with $0.3 \%$ hydrogen peroxide in methanol for $15 \mathrm{~min}$ at room temperature and treatment with normal goat serum (Invitrogen, Carlsbad, CA, USA), the sections were incubated overnight at $4^{\circ} \mathrm{C}$ with rabbit anti-HSP27 polyclonal antibody (ab5579, Abcam) at a dilution of 1:250 (Zymed Labroatories, Invitrogen). Slides were rinsed for $10 \mathrm{~min}$ in PBS wash solution and incubated for 30 min with the HRP-labeled polymer conjugated secondary antibody (EnVision+; DakoCytomation, Carpintera, CA, USA) was applied according to the manufacturer's instructions. A known positive endometrial cancer tissue biopsy sample was used as the positive control. PBS and non-immune serum were used instead of the primary antibody for the blank control and negative control samples, respectively.

HSP27 protein was stained brown in the cytoplasm of cancer cells. The evaluation of HSP27 staining was carried out by two independent observers, and the staining area and intensity were scored separately. Specifically, a score of 0 was assigned to a staining area with $\leq 10 \%$ of the tumor cells, 1 for an area with $11-25 \%$ of the tumor cells, 2 for $26-50 \%$ tumor cells, and 3 for $>51 \%$ tumor cells. For the staining intensity, a score of 0 was assigned for absent/weak staining (negative control), 1 for weak staining markedly stronger than the negative control level, 2 for moderately intense staining, and 3 for intense staining. The final grade of the section was derived from the sum of the staining area and intensity scores. A final score $\geq 3$ was recognized to indicate positive expression. Equivocal stains were considered negative.

\section{Results}

Sensitivity of Capan-1 to GEM. As in our previous study, it was necessary to identify doses of GEM $(2,000 \mu \mathrm{g} / \mathrm{ml})$ in vitro that had fewer than $15 \%$ viable cells after treatment, and the cell viability rate was $6.03 \pm 3.26 \%$. After 7 days of culturing cells in drug-free medium, there was no significant cell mortality. The cells had similar morphology and comparable growth and tumorigenic potential to their untreated parental cells. Repeated subculture affected the cell-cycle profile and growth characteristics of the surviving cells (13). Surviving cells were harvested for protein extraction, at which time the cells were viable, stable, and in some cases, exhibited growth.

Differentially expressed proteins downregulated in the Capan-1 cell line and in stable surviving cells following primary GEM treatment by proteomic analysis. Protein expression was assessed using three samples each of Capan-1 cells cultured under the same conditions. More than 1,000 protein spots were visualized on the 2-DE gels. We adopted a 2-DE analysis to quantitatively compare the protein profiles 
Table I. Differential expression of proteins between the surviving cells of Capan-1 after primary GEM treatment compared with Capan-1 cells without GEM treatment on proteomic analysis.

\begin{tabular}{|c|c|c|c|c|c|}
\hline Spot No & Protein & MW (Da) & $\mathrm{pI}(\mathrm{PH})$ & Protein ID & Protein function \\
\hline 1 & $\begin{array}{l}\text { Guaniune nucleotide-binding protein subunit } \\
\beta \text {-2-like } 1\end{array}$ & 35054 & 7.5645 & 56605 & Signal transduction \\
\hline 2 & Galectin-3 & 26136 & 8.8755 & 31258 & Transport protein \\
\hline 3 & $\begin{array}{l}\text { Proline synthetase co-transcribed bacterial homolog } \\
\text { protein }\end{array}$ & 30324 & 7.2759 & 4351 & Metabolism \\
\hline 4 & Hydroxysteroid $17 \beta$ dehydrogenase-10 & 25967 & 7.025 & 21856 & Transport protein \\
\hline 5 & Proteasome subunit $\alpha$ type- 2 & 25882 & 7.2979 & 16711 & Metabolism \\
\hline 6 & cDNA FLJ52710 & 19784 & 5.9381 & 71428 & Unknown \\
\hline 7 & Lysophospholipase 1 & 22860 & 6.0478 & 25964 & Metabolism \\
\hline 8 & Annexin A1 & 38689 & 6.6359 & 16324 & Signal transduction \\
\hline 9 & Heat shock protein B1(HSP27) & 22768 & 5.9588 & 6789 & Chaperone \\
\hline
\end{tabular}

GEM, gemcitabine; MW, molecular weight.

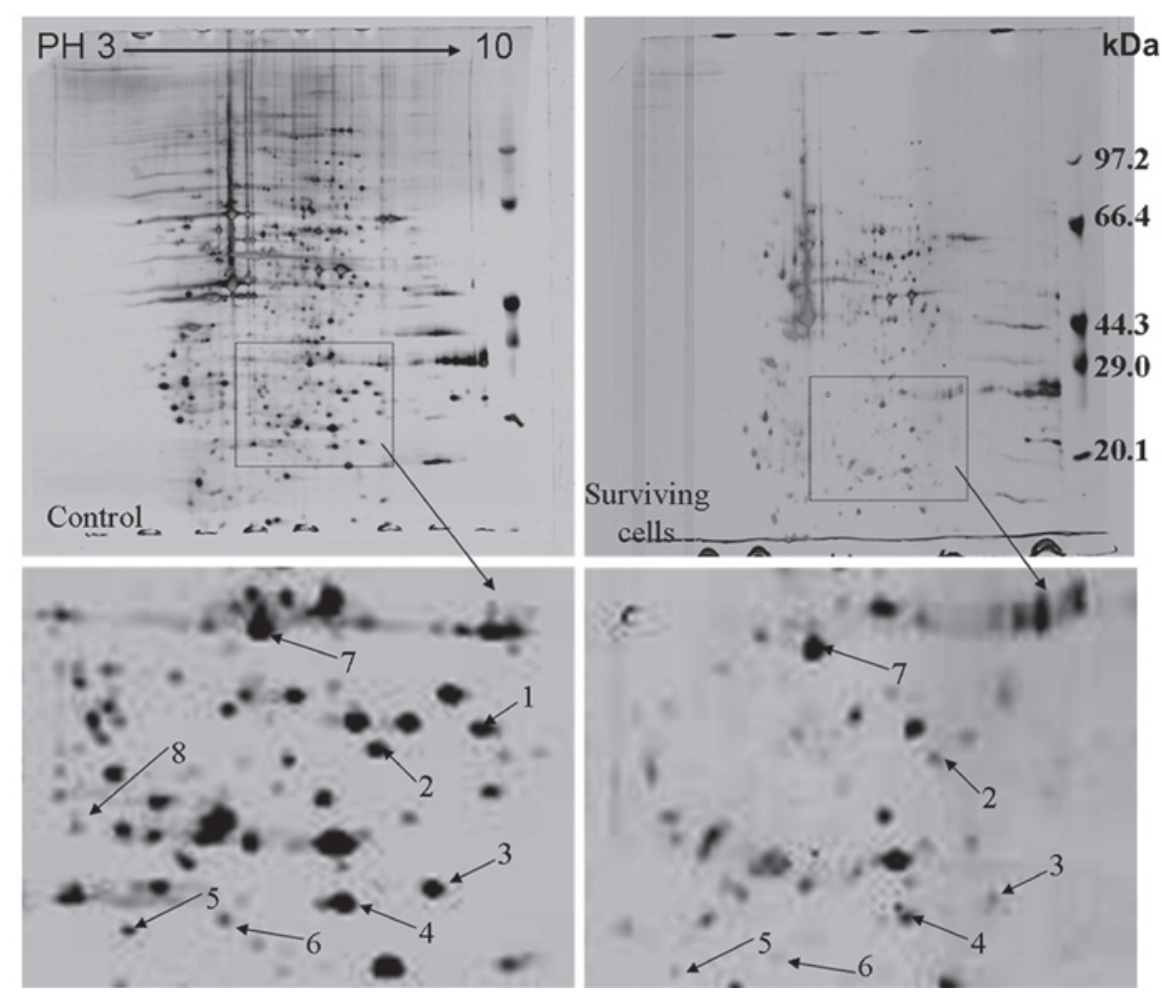

Figure 1. Representative 2-DE gels ( $\mathrm{pH} 3-10 ; \mathrm{NL}, 17 \mathrm{~cm}$ ) showing that 8 protein spots were downregulated in the surviving cells of Capan-1 following primary GEM treatment compared with Capan-1 cells. Lower panel, magnified 2-DE gel images of representative spots (indicated by arrows). NL, non-linear; GEM, gemcitabine.

of the Capan-1 cell line and its stable surviving cells following primary GEM treatment. The differently expressed proteins with more than 1.5-fold changes between the two groups were selected to perform protein identification by liquid chromatography-mass spectrometry analysis. A total of 9 downregulated proteins were successfully identified (Fig. 1). Information on the 9 proteins identified is shown in Table I. Based on their functions, these proteins are mainly involved in signal transduction (guaniune nucleotide-binding protein subunit $\beta$-2-like 1 and annexin A1), transport (galectin-3 and hydroxysteroid $17 \beta$ dehydrogenase-10), metabolism (proline synthetase co-transcribed bacterial homolog protein, proteasome subunit $\alpha$ type-2 and lysophospholipase 1) and as chaperones (heat shock protein $\mathrm{B} 1$ ). There was also one protein with an unknown protein. In this study, we selected HSP27 for further study of intrinsic chemoresistance in pancreatic cancer.

Verification of protein expression by western blot analysis. The differential expression of the Capan-1 cell line and its stable surviving cells following primary GEM treatment iden- 
Table II. Correlation of HSP27 expression with clinicopathological features of pancreatic ductal adenocarcinoma patients.

\begin{tabular}{|c|c|c|c|c|c|c|c|}
\hline \multirow[b]{2}{*}{ Variables } & \multirow[b]{2}{*}{$\mathrm{n}$} & \multicolumn{4}{|c|}{ HSP27 immunoreactivity } & \multirow[b]{2}{*}{ r value } & \multirow[b]{2}{*}{ P-value } \\
\hline & & - & \pm & + & ++ & & \\
\hline \multicolumn{8}{|l|}{ Gender } \\
\hline Male & 28 & 6 & 10 & 9 & 3 & \multirow[t]{2}{*}{0.146} & \multirow[t]{2}{*}{0.326} \\
\hline Female & 19 & 3 & 6 & 5 & 5 & & \\
\hline \multicolumn{8}{|l|}{ Age (yrs) } \\
\hline$\leq 55$ & 23 & 4 & 9 & 8 & 2 & \multirow[t]{2}{*}{0.090} & \multirow[t]{2}{*}{0.548} \\
\hline$>55$ & 24 & 5 & 7 & 6 & 6 & & \\
\hline \multicolumn{8}{|l|}{ Location of tumor } \\
\hline Head & 29 & 6 & 9 & 12 & 2 & \multirow[t]{2}{*}{0.106} & \multirow[t]{2}{*}{0.479} \\
\hline Body/tail & 18 & 3 & 7 & 2 & 6 & & \\
\hline \multicolumn{8}{|l|}{ Histological grade } \\
\hline Well-differentiated & 5 & 1 & 1 & 2 & 1 & \multirow[t]{3}{*}{-0.136} & \multirow[t]{3}{*}{0.361} \\
\hline Moderately differentiated & 37 & 6 & 14 & 10 & 7 & & \\
\hline Poorly differentiated & 5 & 2 & 1 & 2 & 0 & & \\
\hline \multicolumn{8}{|l|}{ Perineural invasion } \\
\hline Present & 25 & 6 & 7 & 8 & 4 & \multirow[t]{2}{*}{0.044} & \multirow[t]{2}{*}{0.768} \\
\hline Absent & 22 & 3 & 9 & 6 & 4 & & \\
\hline
\end{tabular}

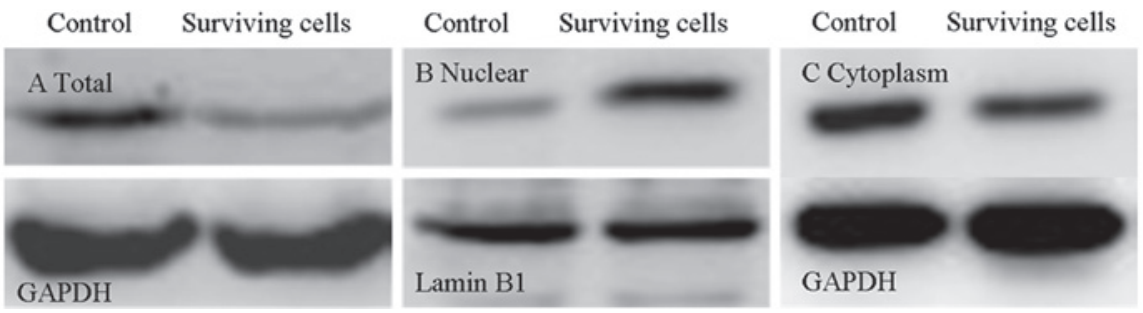

Figure 2. Western blot analysis results revealed that the surviving Capan-1 cells after primary GEM treatment had (A) decreased HSP27 expression; (B) increased HSP27 expression; and (C) decreased HSP27 expression, compared to Capan-1 cells. GEM, gemcitabine.

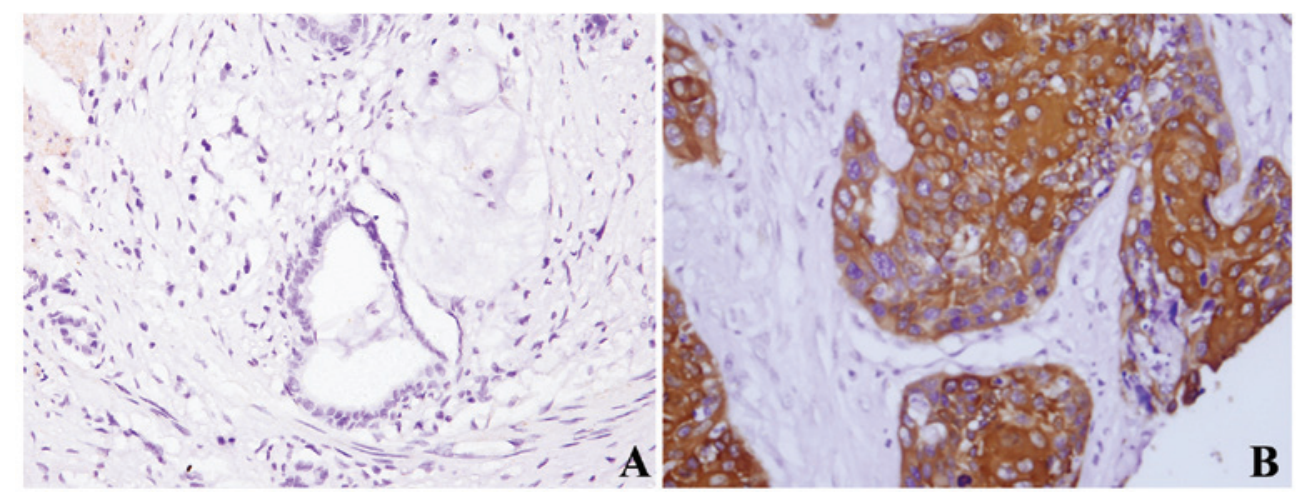

Figure 3. Immunohistochemistry for HSP27 in PDACs and adjacent non-tumor pancreatic tissues. (A) Representative negative or weakly focal HSP27 staining in non-tumorous pancreatic tissue and (B) diffuse cytoplasmic HSP27 staining in moderately differentiated pancreatic cancer. PDACs, pancreatic ductal adenocarcinomas.

tified in the proteomic study were further validated by western blot analysis. As shown in Fig. 2, the surviving cells had a decreased expression level of HSP27 compared to Capan-1 cells, which is consistent with the findings of the proteomic analysis (Fig. 2). The changes of the location of HSP27 indi- cated that HSP27 decreased in the cytoplasm but increased in the nucleus, compared to Capan-1 cells (Fig. 2).

Immunohistochemistry of HSP27 in pancreatic cancer tissues and the correlation with GEM effects and survival. We 
further validated the data by examining expression levels of HSP27 at the protein level. Immunoreactivity was detected in the cytoplasm. Adjacent benign pancreatic parenchyma was negative or weakly focally expressed $(13 \%, 6 / 47)$. Of the 47 PDAC specimens, 38 (81\%) exhibited HSP27 immunoreactivity (Fig. 3). The results of the correlation between tumor HSP27 expression and tumor pathological features are shown in Table II. HSP27 was aberrantly overexpressed in PDACs relative to adjacent non-tumor tissues. However, there was no significant difference between HSP27 levels and other clinicopathological findings such as age, gender, location of tumor, histological grade and perineural invasion in PDAC.

\section{Discussion}

In this study, we applied 2-DE-based proteomics to identify the differentially expressed proteins of pancreatic carcinoma cells that survived GEM primary treatment in vitro. We successfully identified 9 proteins with significantly altered expression levels. Based on their functions, these proteins are mainly involved in signal transduction, transport, metabolism, and as chaperones. One protein has an unknown function. The expression of HSP27 was decreased in a gemcitabine-resistant pancreatic cancer cell line. HSP27 was aberrantly overexpressed in PDACs relative to adjacent nontumor tissues.

HSP27, an ATP-independent chaperone, is involved in a number of processes such as apoptosis, DNA repair and recombination $(14,15)$. HSP27 is upregulated in many types of cancer, including colorectal (16), breast (17), prostate (18) and pancreatic cancer (19). HSP27 may be expressed in a wide range of human cancers and could be a prognostic marker in many cancers (20-22). HSP27 is associated with poor prognosis in non-small cell lung carcinoma (23) and gastric cancer (24), as well as pancreatic ductal adenocarcinoma $(22,25)$. However, HSP27 is associated with good prognosis in esophageal cancer, oral squamous cell carcinoma and malignant fibrous histiocytoma $(23,26)$. These results suggest that HSP27 may have different functions in various types of cancer. There is evidence that HSP27 is involved in anti-cancer resistance, which is related to its location in many cancer cells. Vargas-Roig et al (27) found that, following drug administration, cytoplasmic HSP27 decreased or disappeared in 5 cases $(36 \%)$, increased in 5 cases and remained unchanged in 4 cases (28\%). Following chemotherapy, HSP27 was expressed in the nuclear compartment in 10 cases $(71 \%)$; this increase was statistically significant $(\mathrm{P}=0.007)$. Increased HSP27 expression is correlated with higher rates of GEM resistance in patients with pancreatic cancer. Furthermore, knock-out of HSP27 reduces chemoresistance $(28,29)$. RP101 (brivudine) may bind to heat shock protein HSPB1 (HSP27) and enhances survival in animals and pancreatic cancer patients (30). As previously shown, HSP27 may be phosphorylated and translocated to the nucleus under different circumstances and exposed to different stresses regulated by multiple steps (31). The phosphorylation status of HSP27 plays a key role in GEM-induced growth suppression of pancreatic cancer, and it could also be a possible biomarker for predicting the response of pancreatic cancer patients to treatment with GEM $(32,33)$. The combination of HSP27 knockdown with OGX-427 and chemotherapeutic agents such as GEM may be a novel strategy to inhibit the progression of pancreatic cancer (34). In our study, we found the downregulation of total HSP27 in pancreatic carcinoma cells survived from GEM treatment. Furthermore, we found that HSP27 was decreased in the cytoplasm and increased in the nucleus, and the nuclear expression of HSP27 was always low in immunostaining of pancreatic cancers, which demonstrated that the expression of HSP27 in pancreatic cancer occurs mainly in the cytoplasm. The results indicated that researching the location of HSP27 was more significant for total HSP27 and the different locations of HSP27 had a correlation with cancer chemotherapy resistance. However, the expression of HSP27 in the nucleus was related to the intrinsic chemoresistance of pancreatic cancer cells.

In conclusion, HSP27 may be important in the intrinsic chemoresistance of pancreatic cancer cells and the location of HSP27 in pancreatic cancer cells was more significant compared to the cytoplasmic location. For therapeutic application, a targeted therapy against HSP27 in the nuclear signaling pathway could be applied to overcome GEM resistance and may be beneficial in the treatment of pancreatic cancer. The mechanisms of HSP27 in pancreatic cancer require further research.

\section{Acknowledgements}

This project was supported by the National Key Project of Scientific and Technical Supporting Programs of China (No. 2006BAI02A14) and the National Natural Science Foundation of China (No. 30770996 and No. 81172310).

\section{References}

1. Jemal A, Siegel R, Xu J and Ward E: Cancer statistics, 2010. CA Cancer J Clin 60: 277-300, 2010.

2. Vincent A, Herman J, Schulick R, Hruban RH and Goggins M: Pancreatic cancer. Lancet 378: 607-620, 2011.

3. Kawanami T, Takiguchi S, Ikeda $\mathrm{N}$ and Funakoshi A: A humanized anti-IGF-1R monoclonal antibody (R1507) and/or metformin. Oncol Rep 27: 867-872, 2012.

4. Kasuya K, Tsuchida A, Nagakawa Y, et al: Hypoxia-inducible factor-1alpha expression and gemcitabine chemotherapy. Oncol Rep 26: 1399-1406, 2011.

5. Chen H, Wei W, Guo Y, et al: Enhanced effect of gemcitabine by emodin against pancreatic cancer in vivo via cytochrome C-regulated apoptosis. Oncol Rep 25: 1253-1261, 2011.

6. Di Marco M, Di Cicilia R, Macchini M, et al: Metastatic pancreatic cancer: Is gemcitabine still the best standard treatment? (Review). Oncol Rep 23: 1183-1192, 2010.

7. Burris HA, 3rd, Moore MJ, Andersen J, et al: Improvements in survival and clinical benefit with gemcitabine as first-line therapy for patients with advanced pancreas cancer: a randomized trial. J Clin Oncol 15: 2403-2413, 1997.

8. Neoptolemos JP, Stocken DD, Bassi C, et al: Adjuvant chemotherapy with fluorouracil plus folinic acid vs gemcitabine following pancreatic cancer resection: a randomized controlled trial. Jama 304: 1073-1081, 2010.

9. Banerjee D, Mayer-Kuckuk P, Capiaux G, Budak-Alpdogan T, Gorlick R and Bertino JR: Novel aspects of resistance to drugs targeted to dihydrofolate reductase and thymidylate synthase. Biochim Biophys Acta 1587: 164-173, 2002.

10. Muerkoster S, Wegehenkel K, Arlt A, et al: Tumor stroma interactions induce chemoresistance in pancreatic ductal carcinoma cells involving increased secretion and paracrine effects of nitric oxide and interleukin-1beta. Cancer Res 64: 1331-1337, 2004.

11. Yamauchi K, Yang M, Hayashi K, et al: Induction of cancer metastasis by cyclophosphamide pretreatment of host mice: an opposite effect of chemotherapy. Cancer Res 68: 516-520, 2008. 
12. Wu YJ, Muldoon LL, Dickey DT, Lewin SJ, Varallyay CG and Neuwelt EA: Cyclophosphamide enhances human tumor growth in nude rat xenografted tumor models. Neoplasia 11: 187-195, 2009.

13. Liu QH, Zhang J, Zhao CY, et al: Surviving cells after treatment with gemcitabine or 5-fluorouracil for the study of de novo resistance of pancreatic cancer. Cancer Lett 314: 119-125, 2012.

14. Mosser DD and Morimoto RI: Molecular chaperones and the stress of oncogenesis. Oncogene 23: 2907-2918, 2004.

15. Garrido C, Brunet M, Didelot C, Zermati Y, Schmitt E and Kroemer G: Heat shock proteins 27 and 70: anti-apoptotic proteins with tumorigenic properties. Cell Cycle 5: 2592-2601, 2006.

16. Zhao L, Liu L, Wang S, Zhang YF, Yu L and Ding YQ: Differential proteomic analysis of human colorectal carcinoma cell lines metastasis-associated proteins. J Cancer Res Clin Oncol 133: 771-782, 2007.

17. Kang SH, Kang KW, Kim KH, et al: Upregulated HSP27 in human breast cancer cells reduces Herceptin susceptibility by increasing Her2 protein stability. BMC Cancer 8: 286, 2008.

18. Larkin SE, Holmes S, Cree IA, et al: Identification of markers of prostate cancer progression using candidate gene expression. $\mathrm{Br}$ J Cancer 106: 157-165, 2012.

19. Xia Y, Liu Y, Wan J, et al: Novel triazole ribonucleoside downregulates heat shock protein 27 and induces potent anticancer activity on drug-resistant pancreatic cancer. J Med Chem 52: 6083-6096, 2009.

20. Ciocca DR and Calderwood SK: Heat shock proteins in cancer: diagnostic, prognostic, predictive, and treatment implications. Cell Stress Chaperones 10: 86-103, 2005.

21. Soti C, Nagy E, Giricz Z, Vigh L, Csermely P and Ferdinandy P Heat shock proteins as emerging therapeutic targets. Br J Pharmacol 146: 769-780, 2005.

22. Schafer C, Seeliger H, Bader DC, et al: Heat shock protein 27 as a prognostic and predictive biomarker in pancreatic ductal adenocarcinoma. J Cell Mol Med doi: 10.1111/j.15824934.2011.01473.x., 2011.

23. Berrieman HK, Cawkwell L, O'Kane SL, Smith L and Lind MJ: Hsp27 may allow prediction of the response to single-agent vinorelbine chemotherapy in non-small cell lung cancer. Oncol Rep 15: 283-286, 2006.
24. Yang YX, Xiao ZQ, Chen ZC, et al: Proteome analysis of multidrug resistance in vincristine-resistant human gastric cancer cell line SGC7901/VCR. Proteomics 6: 2009-2021, 2006.

25. Liao WC, Wu MS, Wang HP, Tien YW and Lin JT: Serum heat shock protein 27 is increased in chronic pancreatitis and pancreatic carcinoma. Pancreas 38: 422-426, 2009.

26. Leonardi R, Pannone G, Magro G, Kudo Y, Takata T and Lo Muzio L: Differential expression of heat shock protein 27 in normal oral mucosa, oral epithelial dysplasia and squamous cell carcinoma. Oncol Rep 9: 261-266, 2002.

27. Vargas-Roig LM, Gago FE, Tello O, Aznar JC and Ciocca DR: Heat shock protein expression and drug resistance in breast cancer patients treated with induction chemotherapy. Int J Cancer 79: 468-475, 1998

28. Mori-Iwamoto S, Kuramitsu Y, Ryozawa S, et al: Proteomics finding heat shock protein 27 as a biomarker for resistance of pancreatic cancer cells to gemcitabine. Int J Oncol 31: 1345-1350, 2007.

29. Mori-Iwamoto S, Kuramitsu Y, Ryozawa S, et al: A proteomic profiling of gemcitabine resistance in pancreatic cancer cell lines. Mol Med Report 1: 429-434, 2008.

30. Heinrich JC, Tuukkanen A, Schroeder M, Fahrig T and Fahrig R: RP101 (brivudine) binds to heat shock protein HSP27 (HSPB1) and enhances survival in animals and pancreatic cancer patients. J Cancer Res Clin Oncol 137: 1349-1361, 2011.

31. Arrigo AP: Hsp27: novel regulator of intracellular redox state. IUBMB Life 52: 303-307, 2001.

32. Nakashima M, Adachi S, Yasuda I, et al: Phosphorylation status of heat shock protein 27 plays a key role in gemcitabine-induced apoptosis of pancreatic cancer cells. Cancer Lett 313: 218-225, 2011.

33. Taba K, Kuramitsu Y, Ryozawa S, et al: Heat-shock protein 27 is phosphorylated in gemcitabine-resistant pancreatic cancer cells. Anticancer Res 30: 2539-2543, 2010.

34. Baylot V, Andrieu C, Katsogiannou M, et al: OGX-427 inhibits tumor progression and enhances gemcitabine chemotherapy in pancreatic cancer. Cell Death Dis 2: e221, 2011. 